Supplement of

\title{
Ozone sensitivity to varying greenhouse gases and ozone-depleting substances in CCMI-1 simulations
}

\section{Olaf Morgenstern et al.}

Correspondence to: Olaf Morgenstern (olaf.morgenstern@ niwa.co.nz)

The copyright of individual parts of the supplement might differ from the CC BY 4.0 License. 

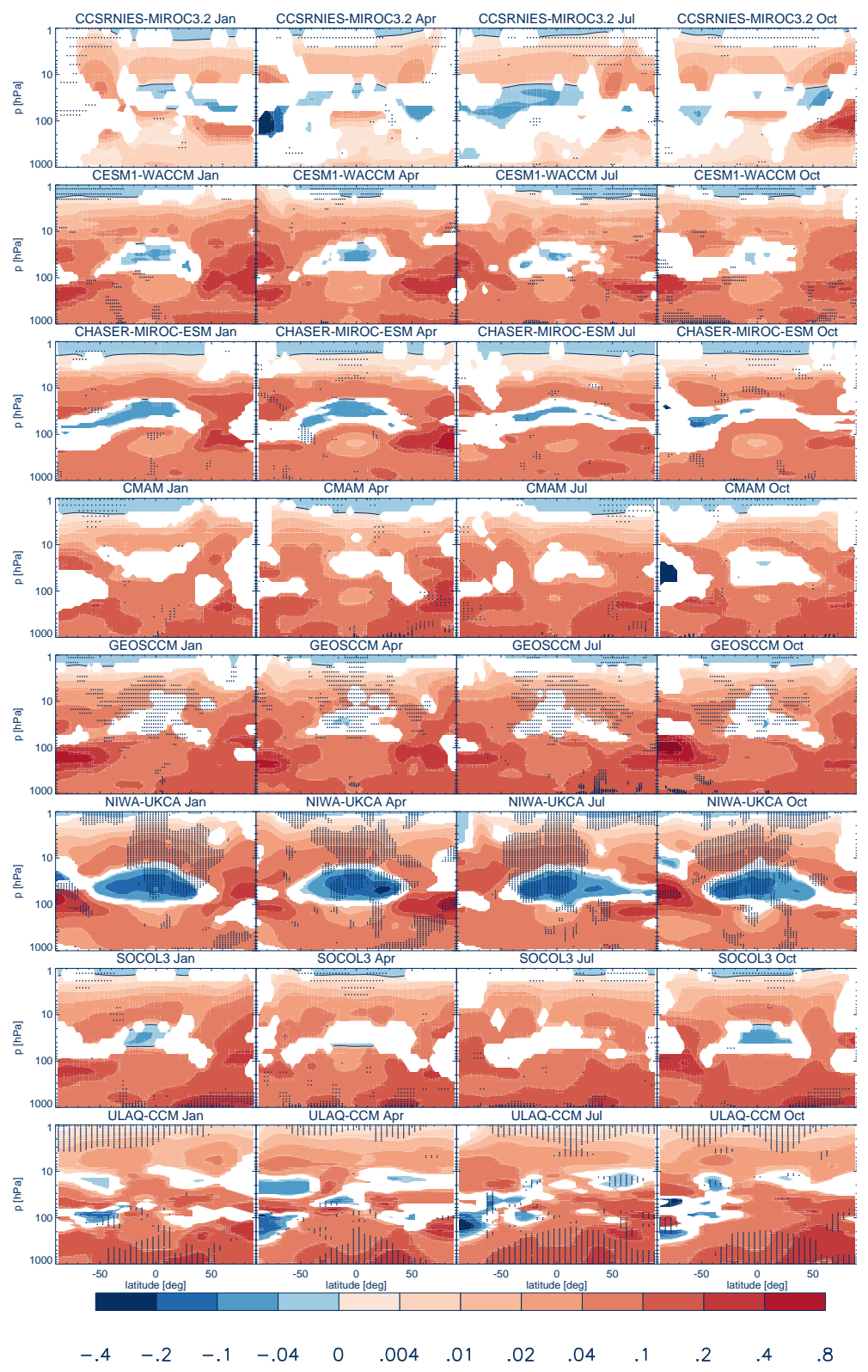

Figure S1: Same as figure 1, but based on ozone concentrations not mixing ratios, in units of $10^{-18}$ molecules $/ \mathrm{cm}^{3} / \mathrm{ppbv}\left(\mathrm{CH}_{4}\right)$. This depiction allows for an easier attribution of total-column changes to changes along the profile. Note the different vertical scale. Stippling denotes regions where the Durbin-Watson criterion (equation E5) is not satisfied. 

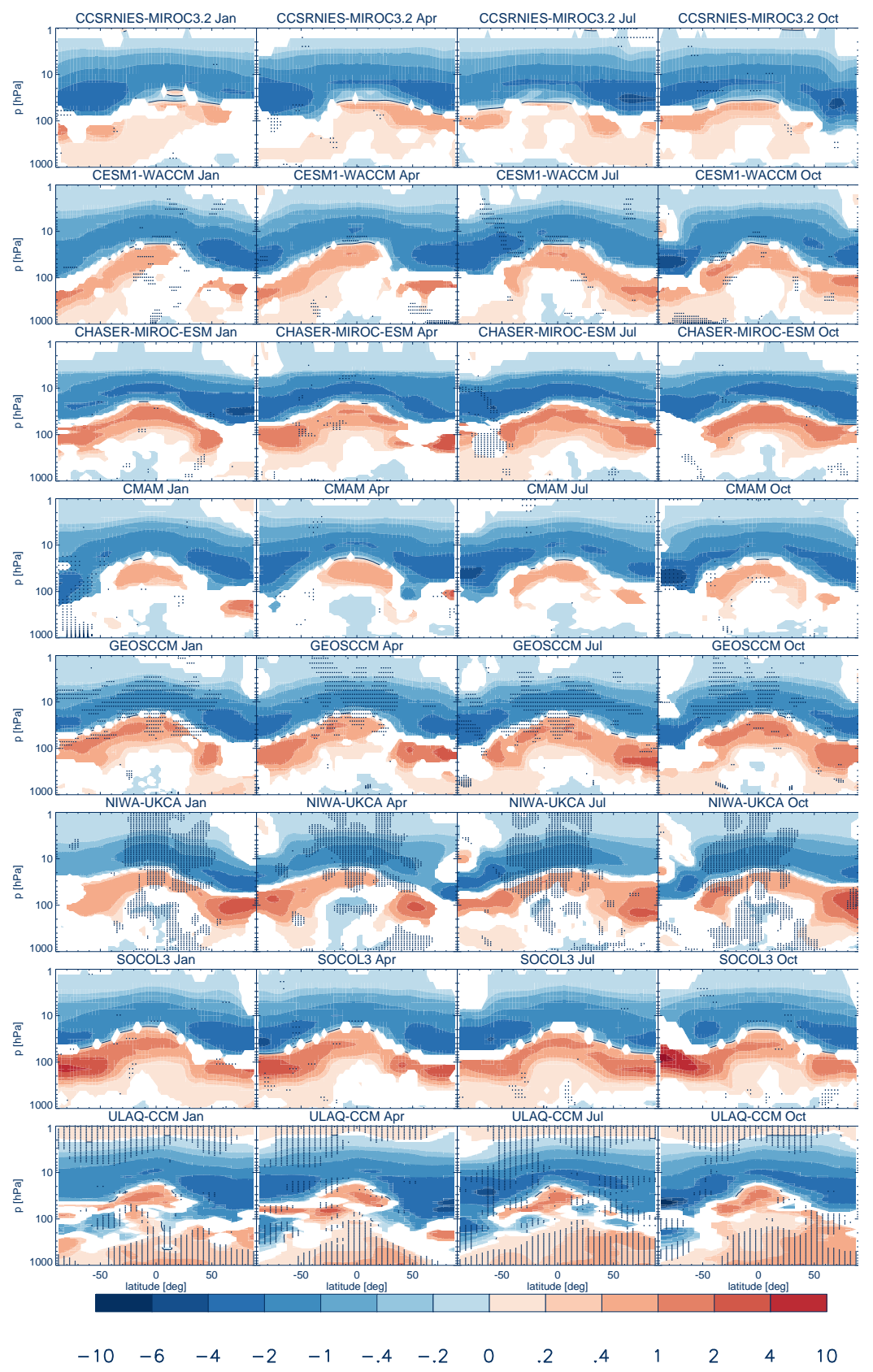

Figure S2: Same as figure 4, but in units of $10^{-18}$ molecules $/ \mathrm{cm}^{3} / \mathrm{ppbv}$. Stippling denotes regions where the Durbin-Watson criterion is not satisfied. 

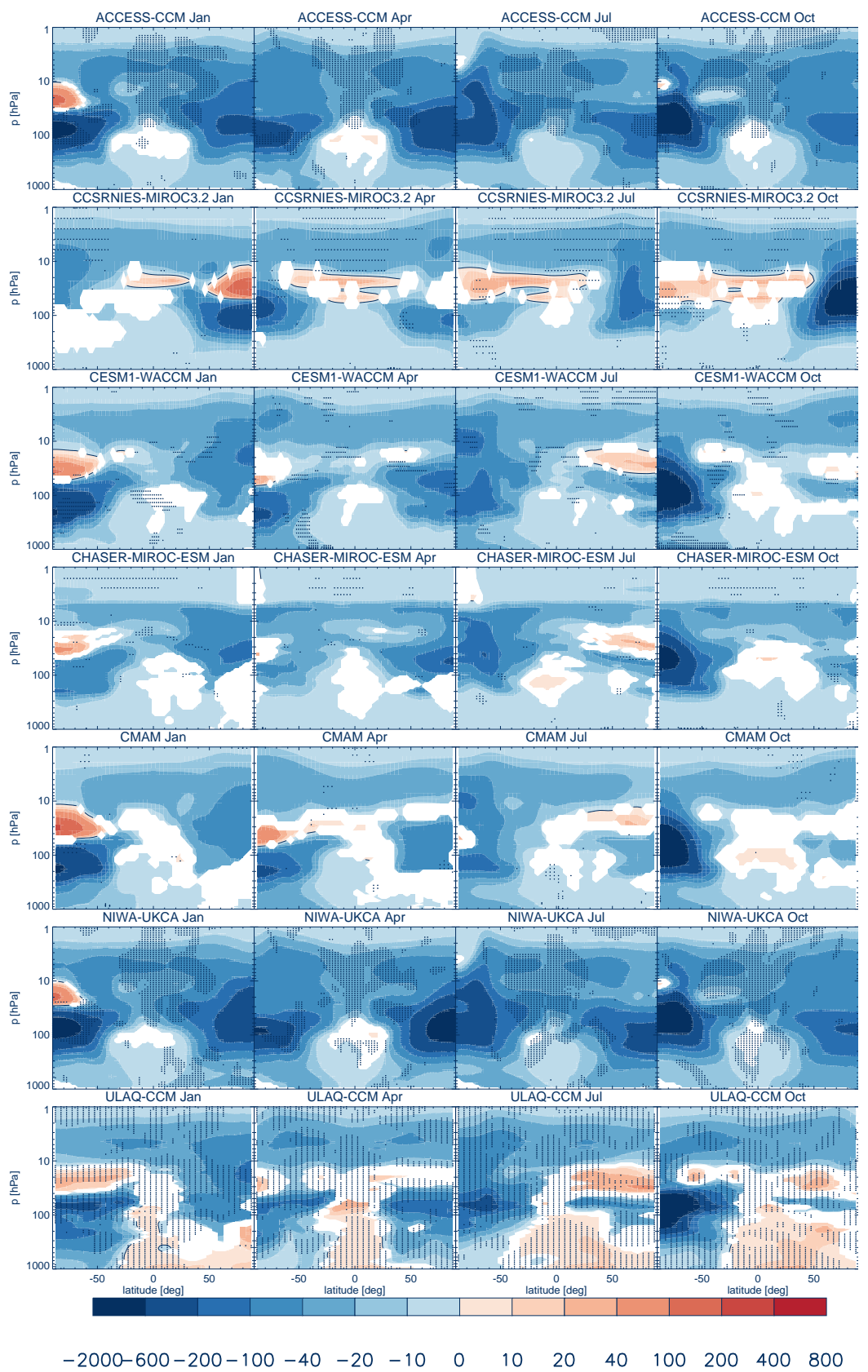

Figure S3: Same as figure 7, but in units of $10^{-18}$ molecules $/ \mathrm{cm}^{3} / \mathrm{ppbv}\left(\mathrm{Cl}^{e q}\right)$. Stippling denotes regions where the Durbin-Watson criterion is not satisfied. 

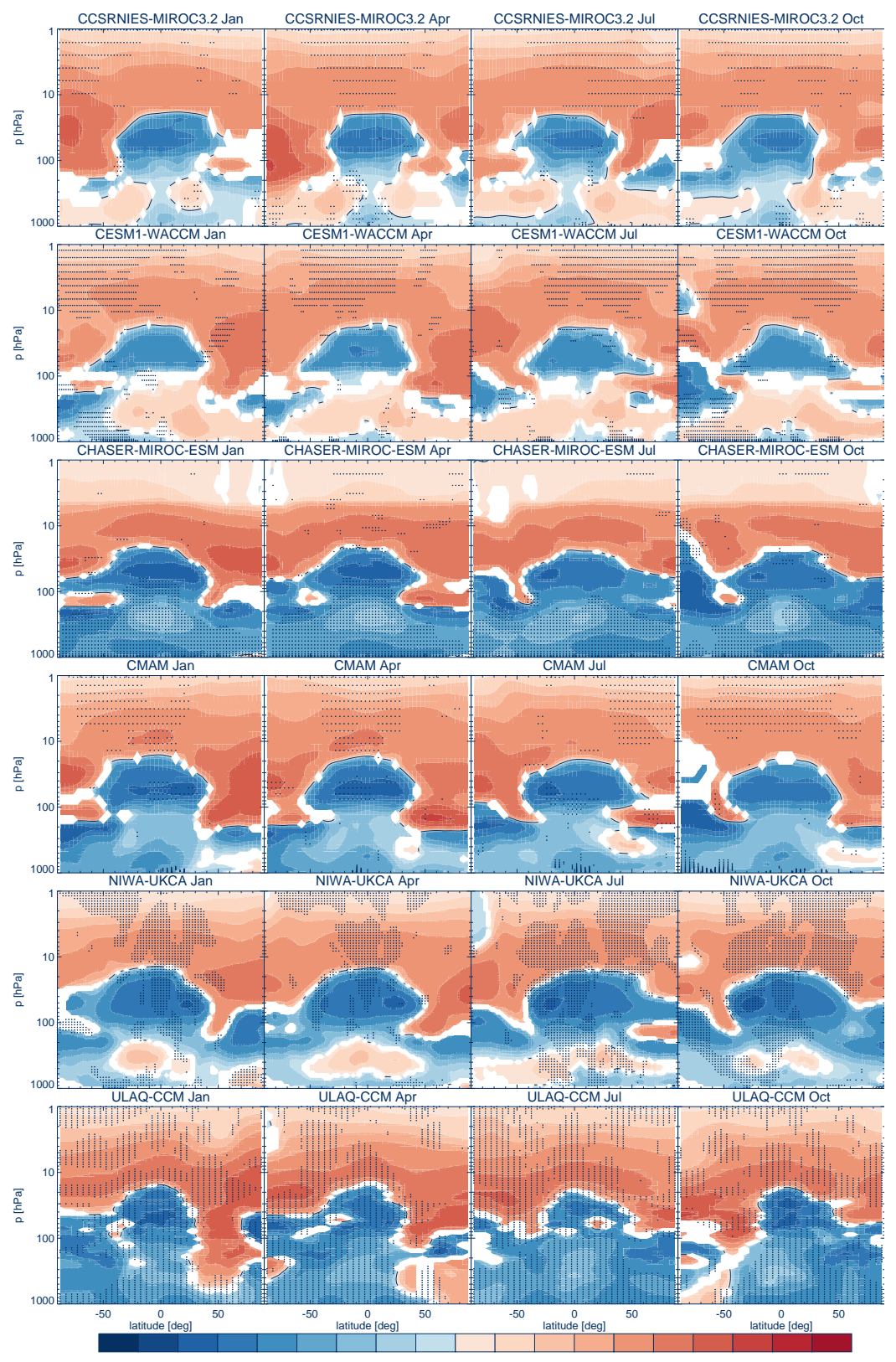

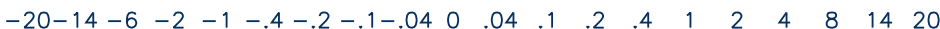

Figure S4: Same as figure 10, but in units of $10^{-15}$ molecules $/ \mathrm{cm}^{3} / \mathrm{ppbv}\left(\mathrm{CO}_{2}^{e}\right)$. Stippling denotes regions where the Durbin-Watson criterion is not satisfied. 

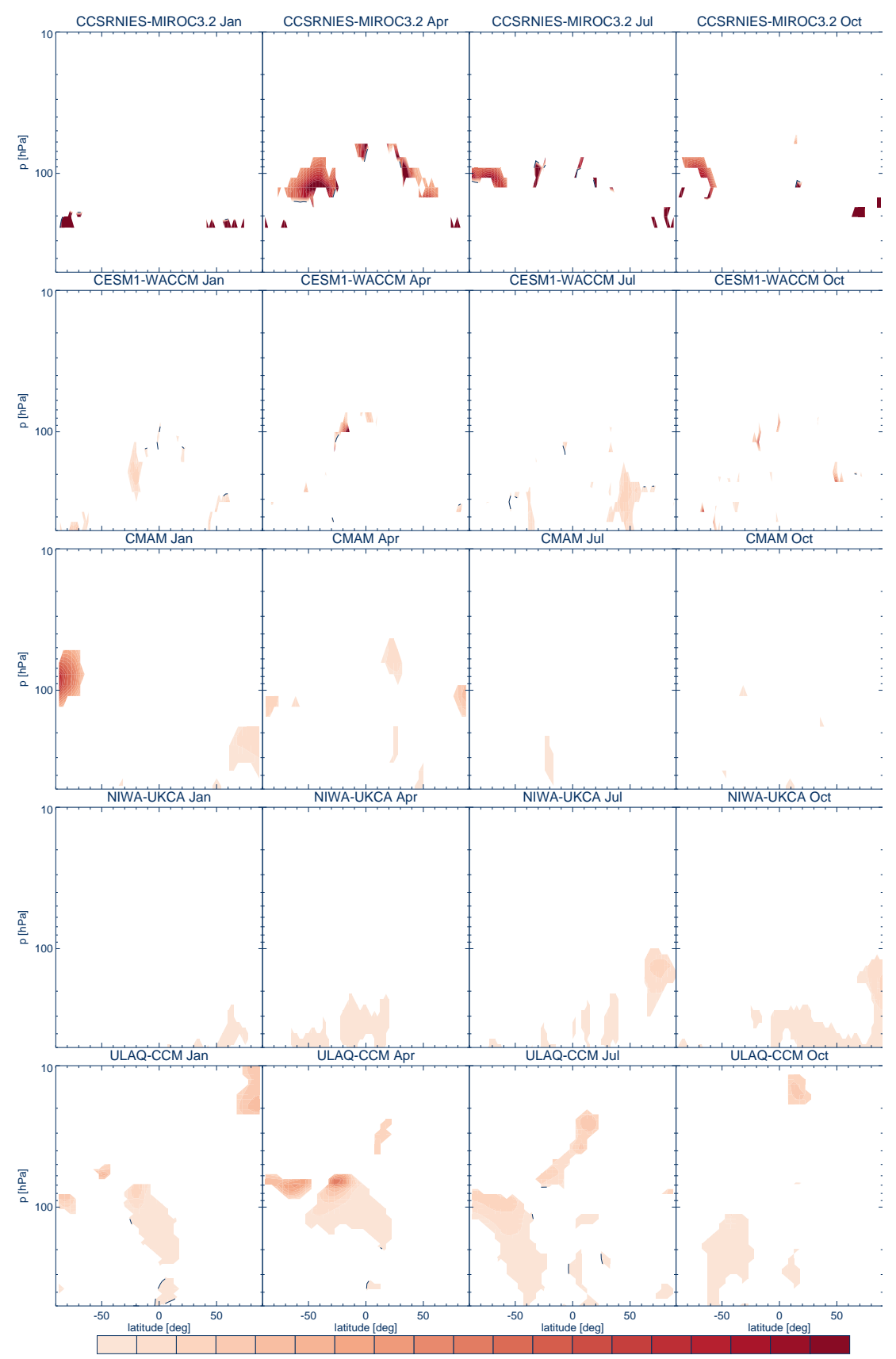

$\begin{array}{llllllllllllllllllll}0 & 2 & 4 & 6 & 8 & 10 & 12 & 14 & 16 & 18 & 20 & 22 & 24 & 26 & 28 & 30 & 32 & 34 & 36 & 38\end{array}$

Figure S5: Ratio of stratospheric AOA increases to increases in surface $\mathrm{N}_{2} \mathrm{O}$, in $10^{-4}$ years/ppbv. 

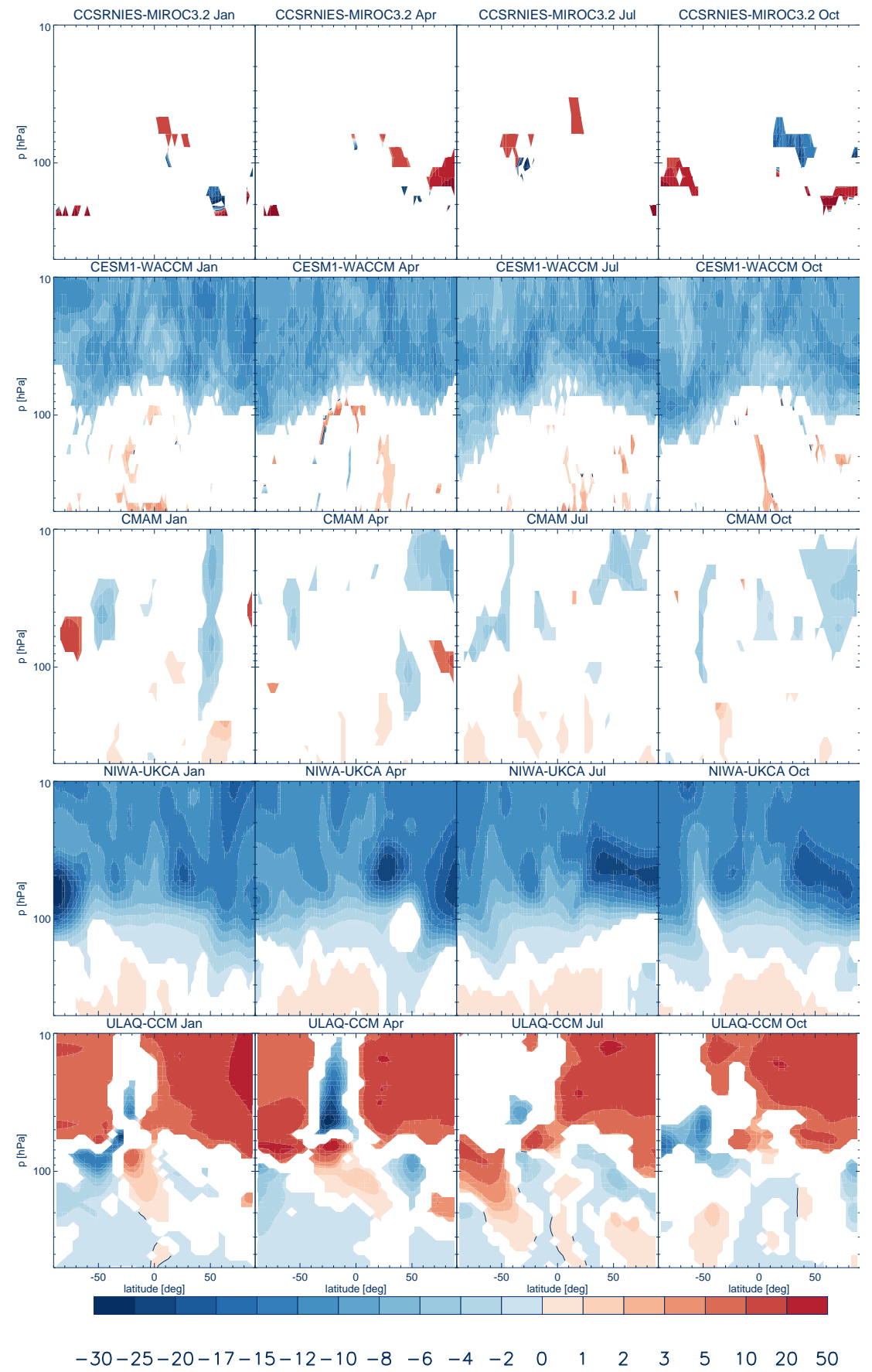

Figure S6: Same as figure S5, but for $\mathrm{CH}_{4}$, in $10^{-5}$ years/ppbv. 

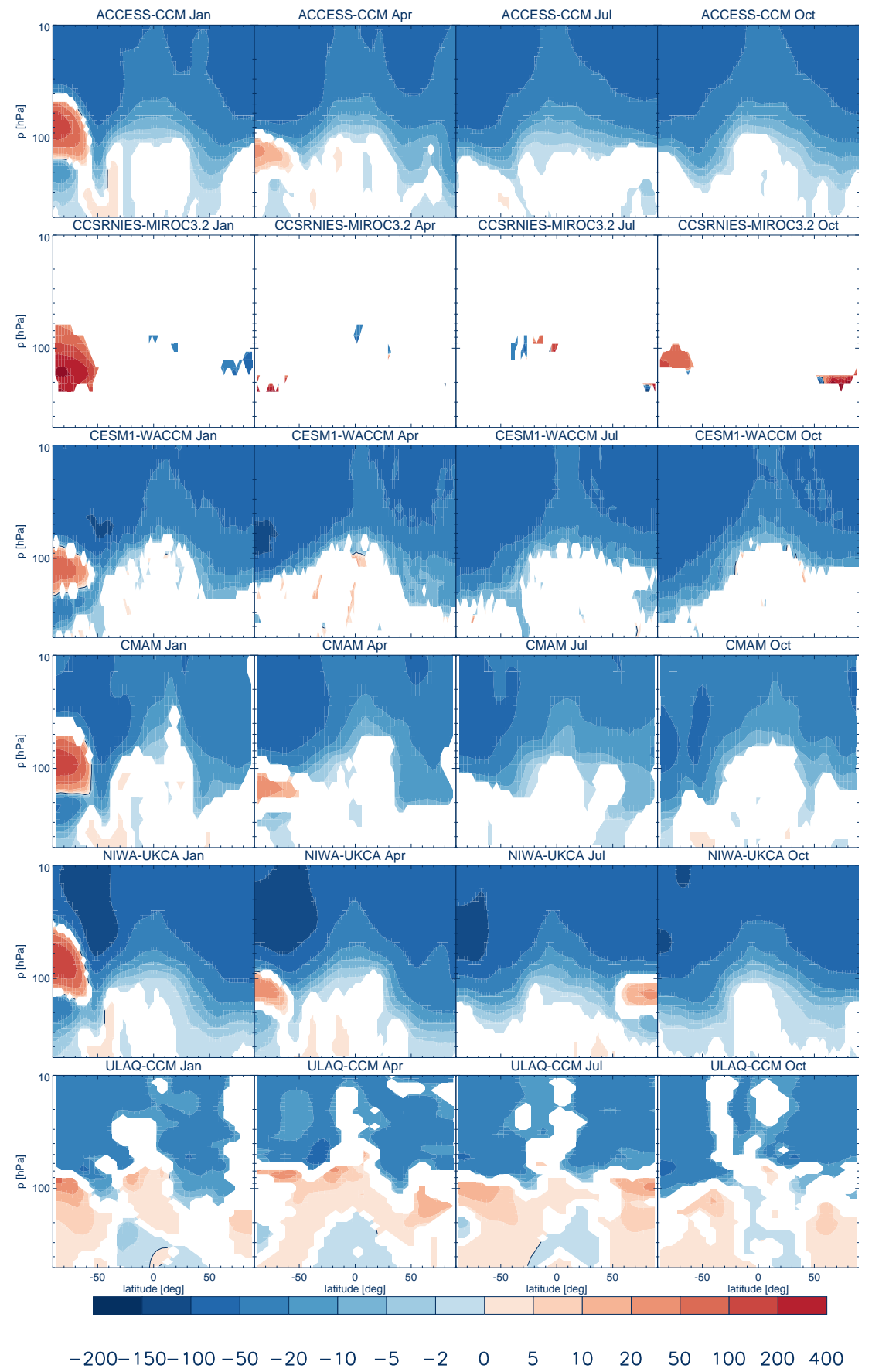

Figure S7: Same as figure S5, but for $\mathrm{Cl}^{\mathrm{eq}}$, in $10^{-6}$ years/pptv. 

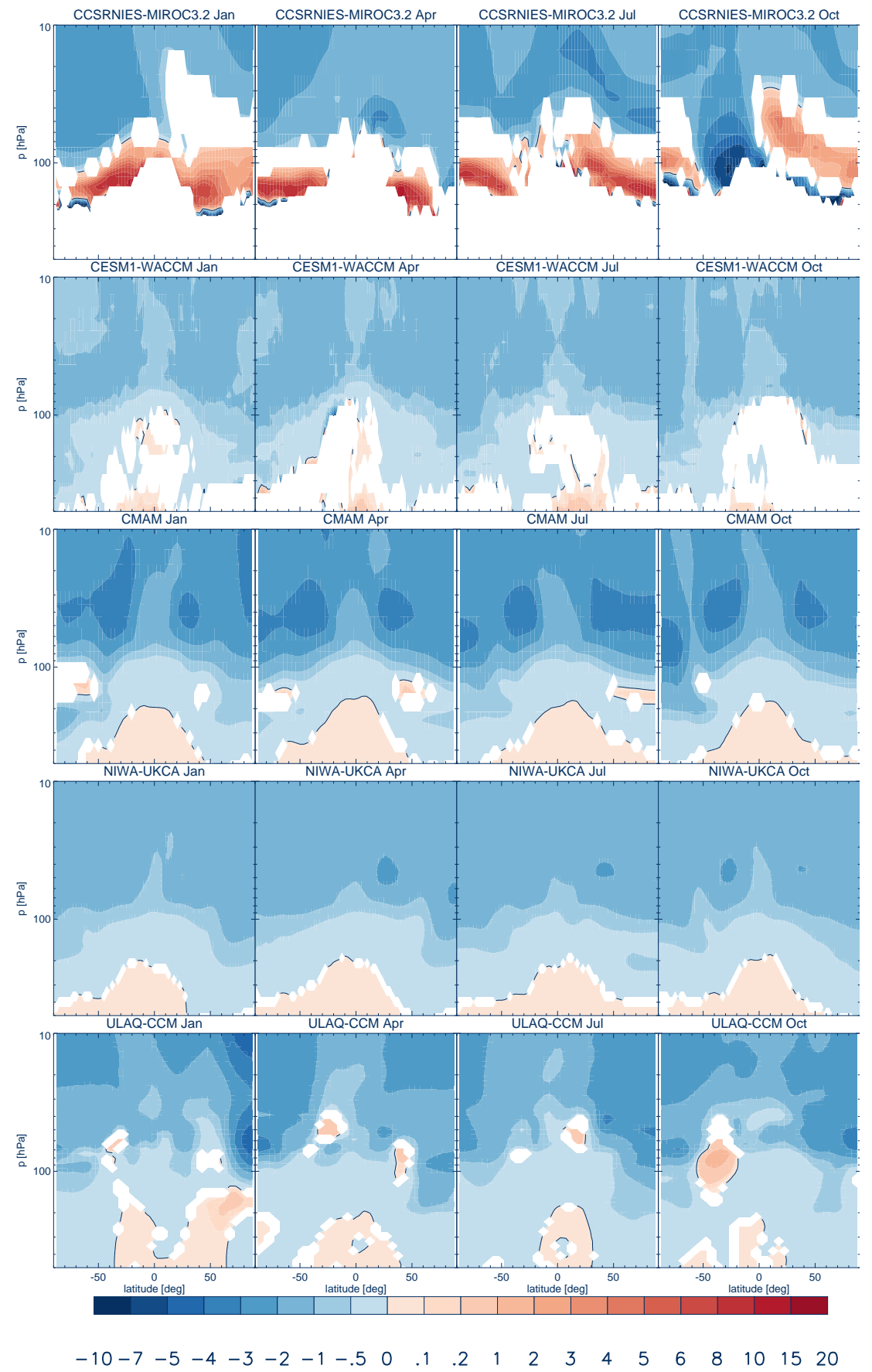

Figure S8: Same as figure S5, but for $\mathrm{CO}_{2}^{\mathrm{e}}$, in $10^{-3}$ years/ppmv. 


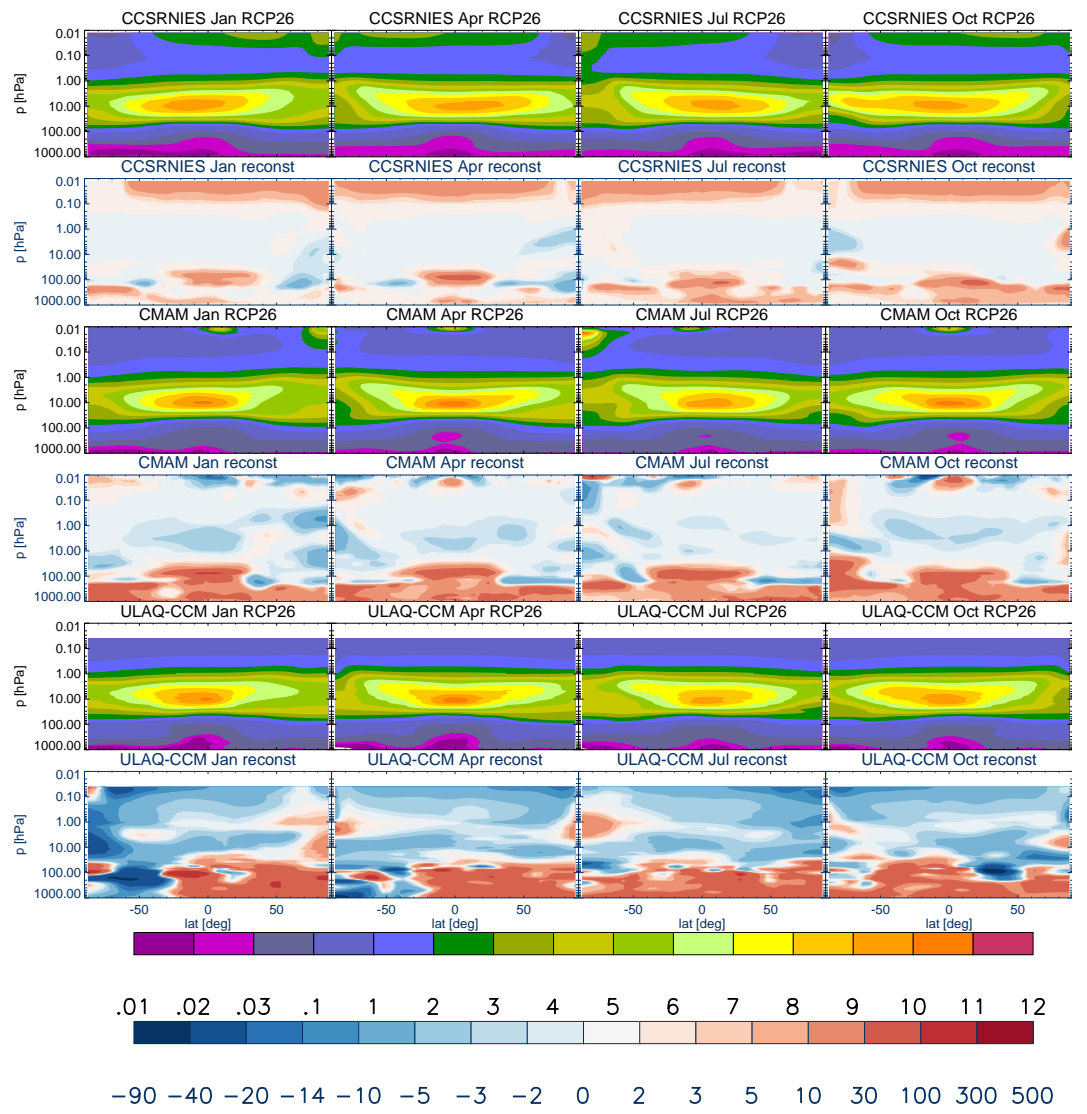

Figure S9: Same as figure 14 but for SEN-C2-RCP26. 

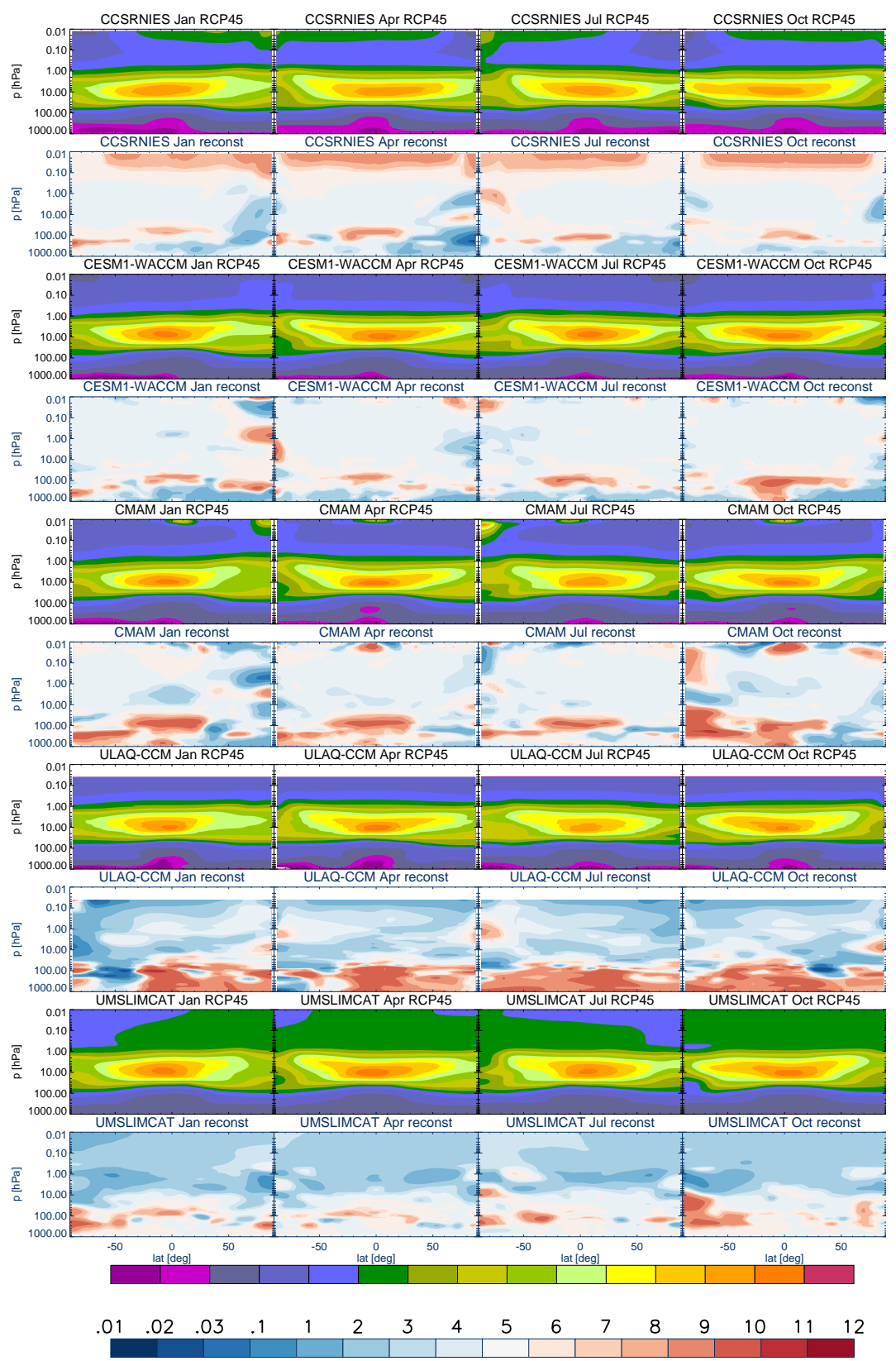

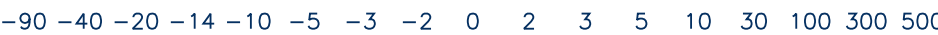

Figure S10: Same as figure 14 but for SEN-C2-RCP45. 